\title{
Some anatomical studies on the arterial supply and venous drainage of the tail of the buffalo "Bos Bubalis L."
}

\author{
M. R. A. Gad, Z. A. Adam, M. G. Tawfiek* \\ Department of Anatomy and Embryology, Faculty of Veterinary Medicine, Beni-Suef University, \\ Beni-Suef 62511, Egypt
}

\begin{abstract}
Twenty tails of buffaloes were used in this study from apparently healthy adult animals. They are dissected to reveal their arteries and veins. Fourteen photographs illustrated the results in the study. The study revealed that the arterial supply of the tail comes from the median caudal, superficial caudal, deep caudal, dorsolateral caudal arteries and the tail is drained by five caudal veins; median caudal, two ventrolateral caudal and two lateral caudal veins.
\end{abstract}

The importance of the buffalo among the livestock in our country as a reproductive animal initiated an increasing interest to establish more accurate and specific studies about its tail. The tail is clinically important due to the using of the median caudal vein for blood collection and intravenous injection, also the median caudal artery is used for pulse determination. Inspite of the anatomical studies on this region in different domestic animals conducted by many authors, there is a lack of available literatures on the vasculature of the tail region in buffaloes (ElAyat, Hagras, Swielim and Abu Zaid, 1983 and Tawfiek, 2007) and in buffalo calves (Gadre, 2000).

\section{Material and Methods}

The material used in the present study included 20 tails were dissected to reveal their arterial architecture. After that ten tails were used to demonstrate their venous drainage.

The arteries and veins were injected with coloured commercial gum milk latex, colored red with carmine for arteries and blue with ultramarine for veins after being rinsed with warm normal saline solution (Hildebrand, 1968). The arteries were injected via the lateral sacral artery and the veins were injected through the median caudal vein. Manual dissection was employed after three days. In order to make the arteries and veins stand out clearly for photographic procedure, they were painted with

\footnotetext{
* Corresponding author. Tel.: +20 0822322066; fax: +200822327982 .

E-mail address: tawfiek@bsu.edu.eg (M. G. Tawfiek).
}

red and blue colored paint respectively. The nomenclature in this study was adopted according to Nomina Anatomica Veternaria (2005).

\section{Results}

Arterial supply of the tail. The tail of the buffalo was shown to be supplied by the arterial blood through the median caudal, superficial caudal, deep caudal and dorsolateral caudal arteries.

A. Caudalis mediana. The median caudal artery (Fig., 1, 2, 4/1) represented the main arterial supply of the tail. It was formed by the union of the two lateral sacral arteries (Fig.,1) at the level of the sacrocaudal articulation. It continued caudally through the vascular groove, which was formed by the hemal processes of the caudal vertebrae in accompany with its homonymous vein. The median caudal artery was embedded between M. sacrocaudalis ventralis medialis of both sides (Fig., 3/5) and covered by the caudal fascia, fat and skin up to its termination at the distal end of the tail (fig., 2/1). Along its course, it gave off superficial and deep branches.

Rami caudales superficiales. The superficial caudal branches were represented by numerous fine branches (Fig., 3/2). They originated from the ventral aspect of the median caudal artery at regular intervals between the adjacent caudal vertebrae to supply the skin, fascia and fat of the tail.

Rami caudales profundae. The deep caudal branches (Fig., 4/3) originated as trunks (Fig., $3 / 3,4 / 2$ ) from the dorsal aspect of the median 


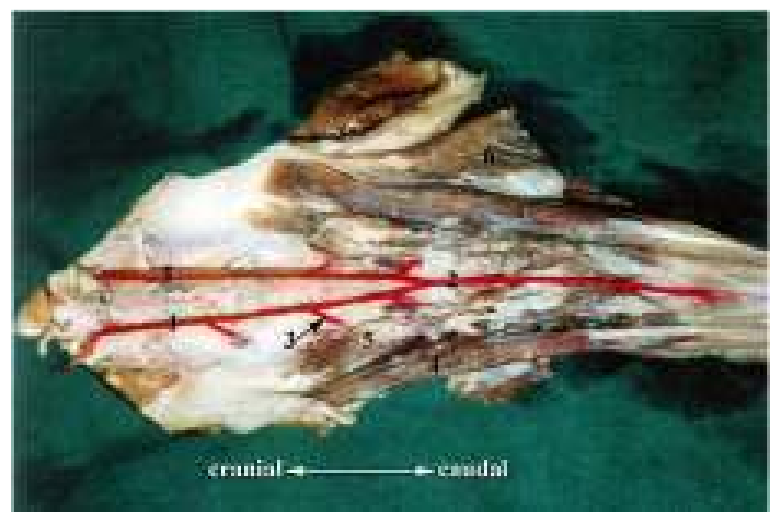

Fig. (1): A photograph of the ventral aspect of the sacrocaudal region of the buffalo, showing origin of the median caudal artery: $1-\mathrm{A}$. Sacralis lateralis, 2- A. Caudalis mediana, 3- Rr. Spinales of A. Sacralis lateralis 4- M. Sacrocaudalis ventralis lateralis, 5- M. Sacrocaudalis ventralis medialis 6- M. Coccygeus.

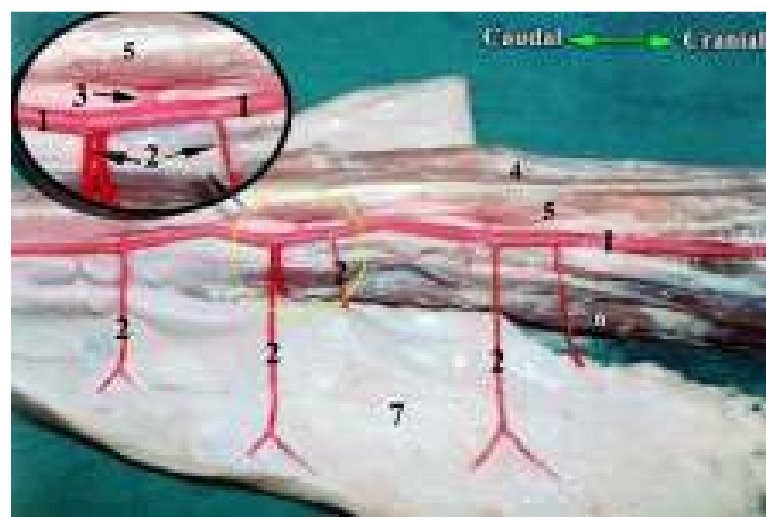

Fig. (3): A photograph of the ventral aspect of the tail of the buffalo, showing origin and distribution of the superficial caudal branches: 1- A. Caudalis mediana, 2- Rr. Caudales superficiales, 3-Common trunk of the right and left deep caudal branches, 4- M. Sacrocaudalis ventralis lateralis, 5- M. Sacrocaudalis ventralis medialis, 6Mm. Intertransversarii caudae 7- Skin and fascia of the tail.

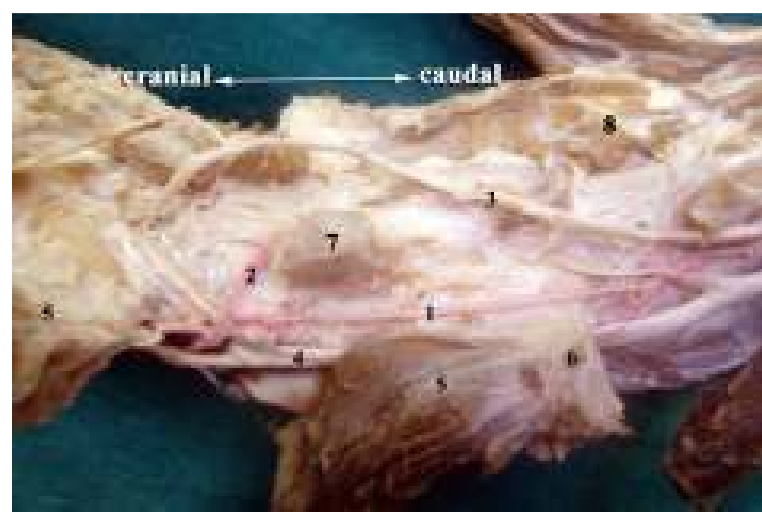

Fig. (5): A photograph of the dorsolateral aspect of the tail of the buffalo, showing the dorsolateral caudal artery and its branches: 1- A. Caudalis dorsolateralis, 2- Rr. Caudales dorsales, 3- Plexus caudalis dorsalis 4- Plexus caudalis ventralis, 5- $\mathrm{Mm}$. Intertransversarii caudae, 6- Processus transversus of vertebrae caudales, 7-Processus articularis cranialis of vertebrae caudales, 8- Processus spinosus of vertebrae caudales.

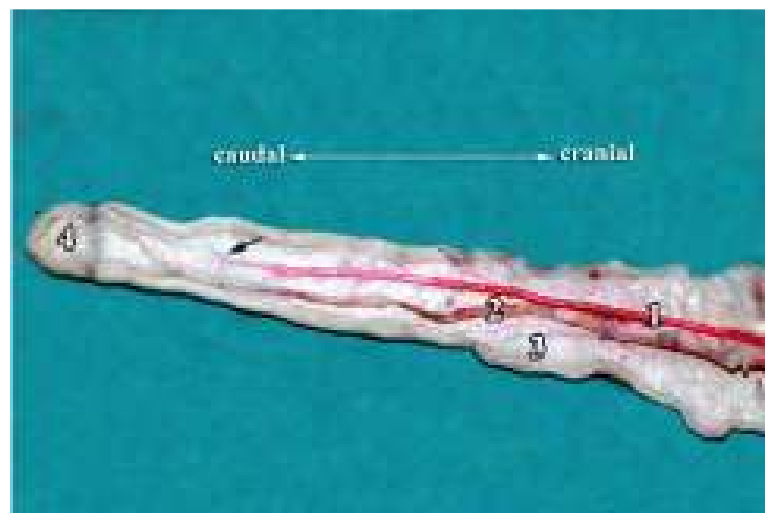

Fig. (2): A photograph of the ventral aspect of distal end of the tail of the buffalo, showing termination of the median caudal artery: 1- A. Caudalis mediana, 2- Last caudal vertebra, 3- Skin of the distal end of the tail 4- Tip of the tail, Arrow indicates the termination of the A. Caudalis mediana.

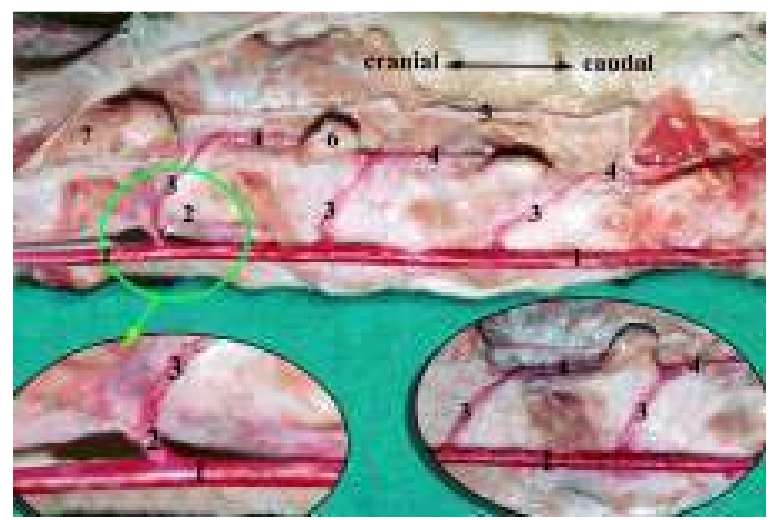

Fig. (4): A photograph of the ventrolateral aspect of the tail of the buffalo, showing origin and distribution of the deep caudal branches: 1- A. Caudalis mediana, 2- Common trunk of the right and left deep caudal branches, 3- Rr. Caudales profundae, 4- A. Caudalis dorsolateralis, 5- Plexus caudalis dorsalis 6Processus transversus of the caudal vertebrae, 7- $\mathrm{Mm}$. Intertransversarii caudae.

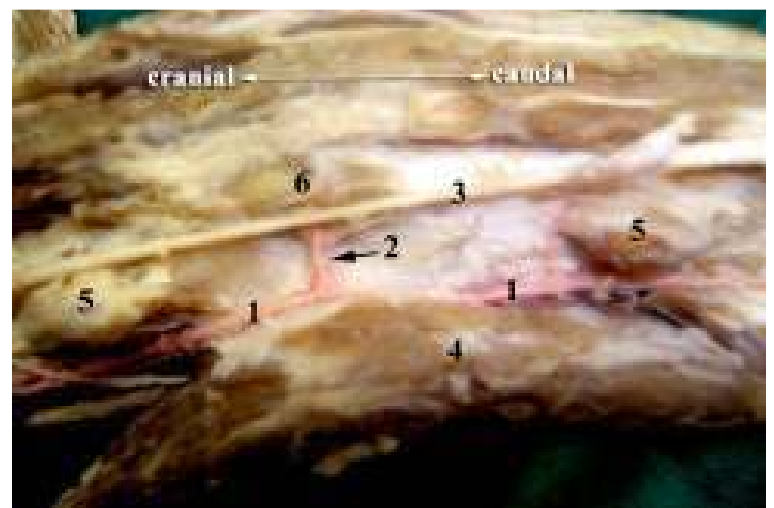

Fig. (6): A photograph of the dorsolateral aspect of the tail of the buffalo, showing the dorsal caudal branches: 1- A. Caudalis dorsolateralis, 2- Rr. Caudales dorsales, 3- Plexus caudalis dorsalis 4- Mm. Intertransversarii caudae, 5- Processus articularis cranialis of vertebrae caudales, 6- Processus spinosus of vertebrae caudales. 


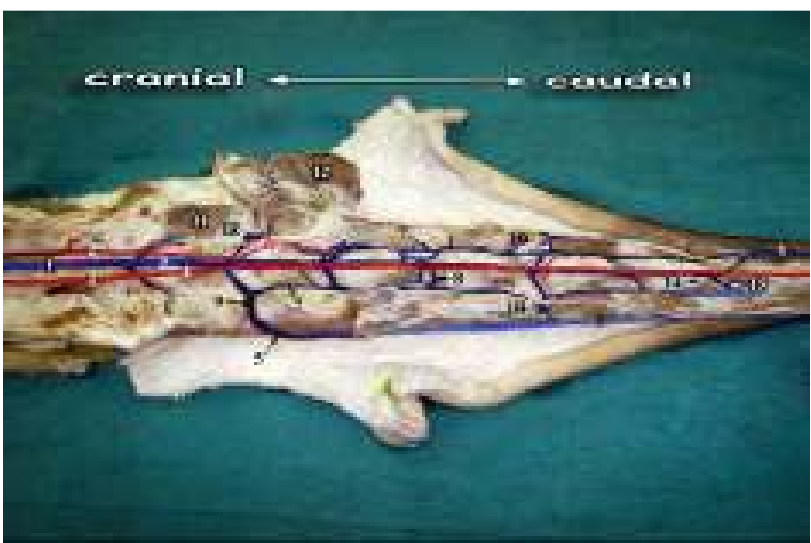

Fig. (7): A photograph of the ventral aspect of the sacrocaudal region of the buffalo, showing the origin and distribution of the tail veins: 1- V. Sacralis mediana, 2- A. Sacralis lateralis, 3- V. Caudalis mediana, 4- A. caudalis mediana, 5- V. caudalis lateralis dextra, 6V. caudalis lateralis sinsitra, 7- V. caudalis Ventrolateralis, 8- Rr. Caudales, 9- Anastmosing between 3, 5\&7, 10- Anastmosing between the lateral and ventrolateral caudal veins, 11- Mm. Intertransversarii caudae, 12- M. Coccygeus, 13- Processus transversus of the caudal vertebra I, 14- Body of the caudal vertebra VII, 15- Terminal branches of V. caudalis mediana.

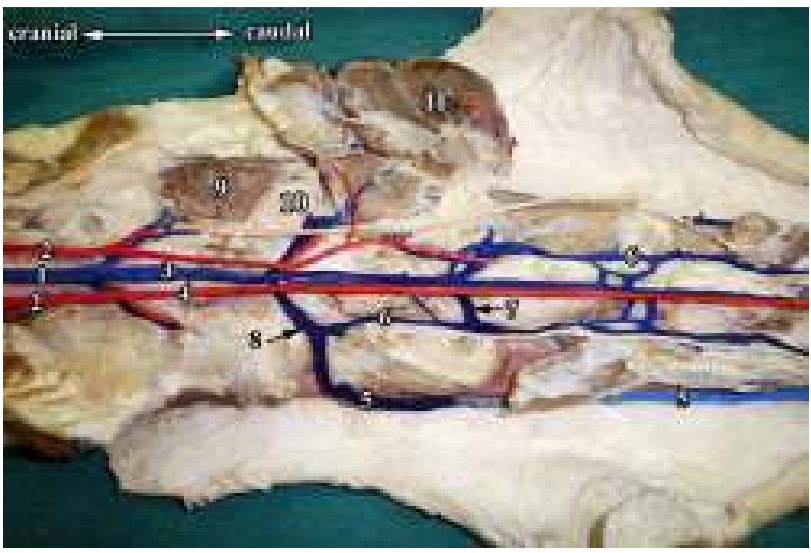

Fig. (9): A photograph of the right side of the sacrocaudal region of the buffalo (Ventral view), showing the right lateral caudal vein: 1- V. Sacralis mediana, 2- A. Sacralis lateralis, 3- V. Caudalis mediana, 4- A. Caudalis mediana, 5- V. Caudalis lateralis dextra, 6V. Caudalis ventrolateralis, 7- Rr. Caudales, 8Anastmosing between 3,5\&6,9- Mm. Intertransversarii caudae, 10- Processus transversus of the caudal vertebra I , 11- M. Coccygeus.

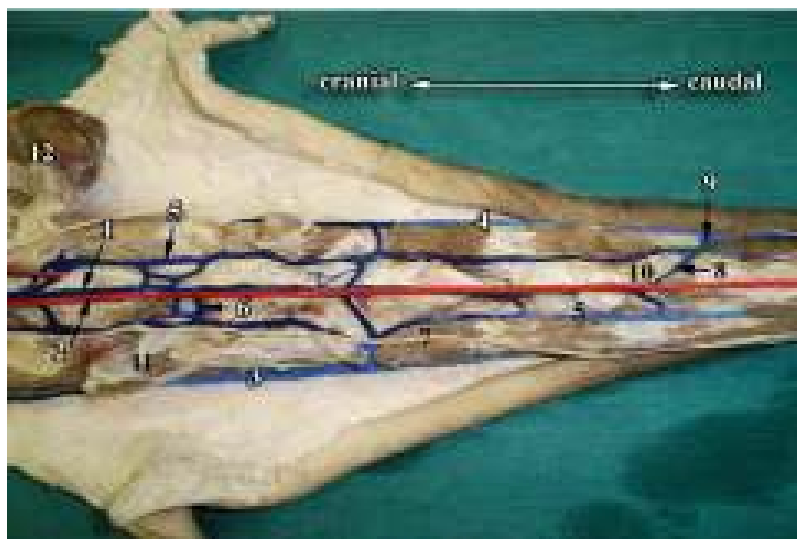

Fig. (8): A photograph of the ventral aspect of the proximal third of the tail of the buffalo, showing the origin and distribution of the tail veins: 1- V. Caudalis mediana, 2- A. Caudalis mediana 3- V. Caudalis lateralis dextra, 4- V. Caudalis lateralis sinistra, 5- V. Caudalis ventrolateralis, 6- Rr. Caudales, 7- Plexus caudalis ventralis, 8- Terminal branches of $\mathrm{V}$. Caudalis mediana, 9- Anastmosing branch between 3, 5 .\& 8, 10- Body of the caudal vertebra VII, 11- Mm. Intertransversarii caudae, 12- M. Coccygeus.

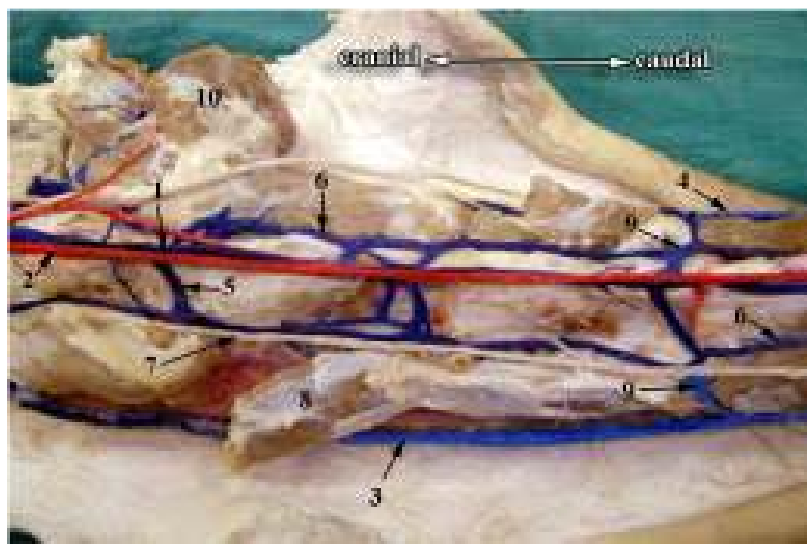

Fig. (10): A photograph of the proximal third of the right side of the tail of the buffalo (Ventrolateral view): 1- V. Caudalis mediana, 2- A. Caudalis mediana, 3- V. Caudalis lateralis dextra, 4- V. Caudalis lateralis sinistra, 5- Rr. Caudales, 6- V. Caudalis ventrolateralis, 7- Plexus caudalis ventralis, 8- Mm. Intertransversarii caudae, 9- Anastmosing between lateral caudal and ventrolateral caudal veins, 10- M. Coccygeus. 


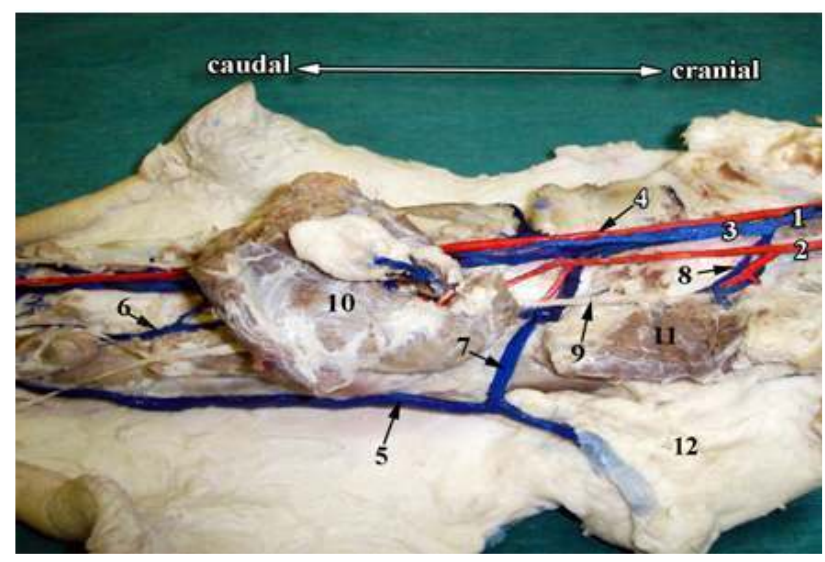

Fig. (11): A photograph of the left side of the tail of the buffalo, showing the left lateral caudal vein (Ventrolateral view): 1- V. Sacralis mediana, 2- A. Sacralis lateralis, 3- V. Caudalis mediana,4- A. Caudalis mediana, 5- V. caudalis lateralis sinistra, 6- V. Caudalis ventrolateralis, 7- Anastmosing between 3\&5, 8- Rr. Spinales, 9- Plexus caudalis ventralis, 10- M. Coccygeus, 11- Mm. Intertransversarii caudae, 12- Fat and fascia of the tail

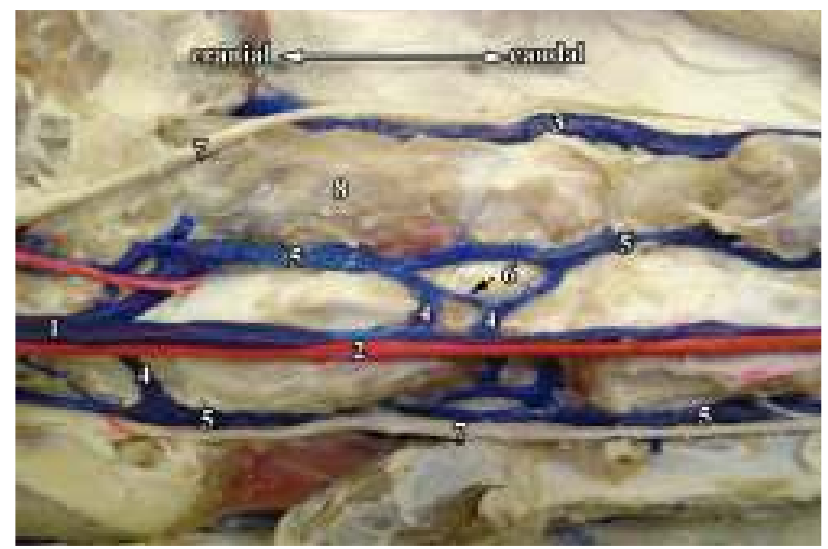

Fig. (13): A photograph of the tail of the buffalo at the level of the third and fourth caudal vertebrae (Ventral view), showing the ventrolateral caudal veins and caudal branches: 1- V. Caudalis mediana, 2- A. caudalis mediana, 3- V. caudalis lateralis sinistra, 4- Rr. Caudales, 5- V. caudalis ventrolateralis, 6- Arcs formed between Rr. Caudales, 7- Plexus caudalis ventralis, 8- $\mathrm{Mm}$. Intertransversarii caudae.

caudal artery. These trunks were immediately divided into relatively large right and left branches. Each of them coursed caudodorsally, deep to the ventral coccygeal muscles and $M$. intertransversarii caudae and gained the dorsal aspect of the transverse processes of the corresponding caudal vertebra and anastmosed with the corresponding ones of the respective side, and constituted the dorsolateral caudal artery (Fig., 4/4, 5/2, 6/1).

A. Caudalis dorsolateralis. The dorsolateral caudal artery ((Fig., 4/4, 5/2, 6/1) continued caudally under cover of $\mathrm{M}$. sacrocaudalis dorsalis lateralis in accompany with the dorsal

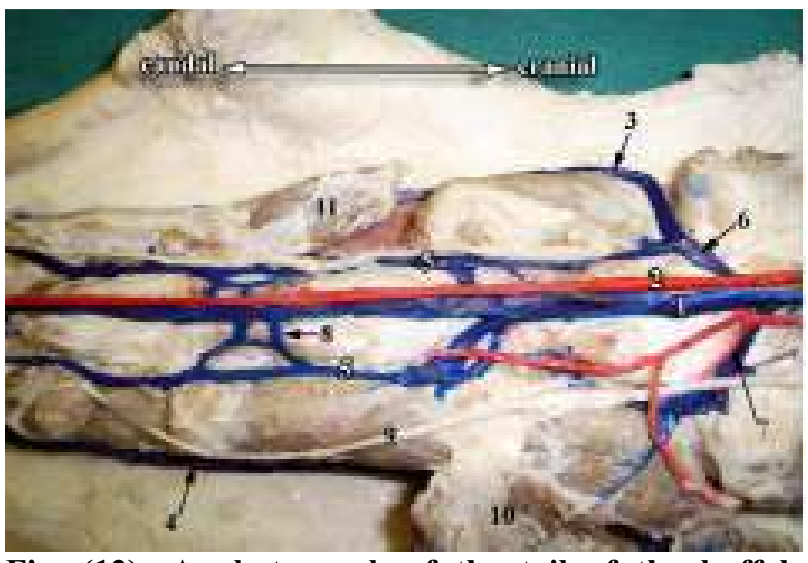

Fig. (12): A photograph of the tail of the buffalo (Ventrolateral view), showing the ventrolateral caudal vein: 1- V. Caudalis mediana, 2- A. caudalis mediana, 3V. Caudalis lateralis dextra, 4- V. Caudalis lateralis sinistra, 5- V. Caudalis ventrolateralis, 6- Anastmosing between 1, 3 \& 5, 7- Anastmosing between 1, 4 \& 5, 8Rr. Caudales, 9- Plexus caudalis ventralis, 10- M. Coccygeus 11- Mm. Intertransversarii caudae.

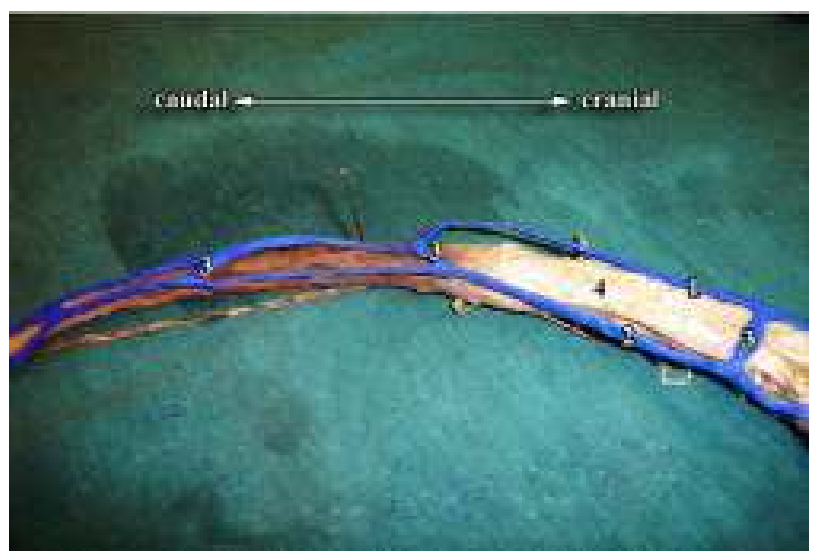

Fig. (14): A photograph of the distal end of the tail of the buffalo (Dorsal view): 1- V. caudalis lateralis sinistra, 2- V. caudalis lateralis dextra, 3- Arcs formed between $1 \& 2,4$ - Dorsal aspect of the distal end of the tail.

caudal nerve plexus of the same side (Fig., 4/5, 5/3, $6 / 3$ ) to terminate at the distal end of the tail. Along its course, the dorsolateral caudal artery, issued small muscular branches to $\mathrm{Mm}$. intertransversarii caudae and detached several small rami caudales dorsales (Fig., 5, 6/2). These small branches ascended and supplied the M. Sacrocaudalis dorsalis lateralis and M. sacrocaudalis dorsalis mediales of the respective side.

II- Venous drainage of the tail. The tail of the buffalo was drained by five caudal veins; median caudal, two ventrolateral caudal and two lateral caudal veins. 
V. caudalis mediana. The median caudal vein (Fig. 7, 13/1) represented the caudal continuation of the median sacral one in the region of the tail (Fig., 7, 9, 11). It was directed caudally on the left side of its homonymous artery up to the fifth caudal vertebra, where it gained the dorsal aspect of this artery.

At the level of the seventh caudal vertebra (Fig., 7, 8), the median caudal vein was terminated by two small branches (Fig., 7, 8), which anastmosed with the lateral and ventrolateral caudal veins.

Along its course and regularly at the intervertebral articulations, the median caudal vein released 2-3 small caudal branches (Fig., 5, $10,12,13)$, which anastmosed with each other to form arcs (Fig., 13/6) deep to the M. sacrocaudalis ventralis medialis, subsequently these arcs anastmosed with each other to constitute the ventrolateral caudal vein.

Vv. Caudales Ventrolaterales. The ventrolateral caudal veins (Fig., 7, 13) of both sides coursed along the ventral aspect of the transverse processes of the corresponding caudal vertebra and $\mathrm{Mm}$. intertransversarii caudae and dorsal to the $M$. sacrocaudalis ventralis lateralis. The ventrolateral caudal vein anaestmosed with the lateral caudal one by several considerable branches (Fig., 7, 10) at irregular intervals.

At the level of the seventh caudal vertebra, the ventrolateral caudal vein was terminated by 2-3 small branches, which anastmosed with the lateral caudal vein and terminal branches of the median caudal one. During its course, the ventrolateral caudal vein drained the $\mathrm{Mm}$. intertransversarii caudae and ventral muscles of the tail.

Vv. Caudales Laterales. The lateral caudal vein (Fig., 7) passed on the lateral aspect of the tail, between the $M$. sacrocaudalis dorsalis lateralis and $\mathrm{Mm}$. intertransversarii caudae and it was covered by the caudal fascia and skin of the tail. Behind the transverse processes of the first caudal vertebra (Fig., 7, 9, 11), the lateral caudal vein anastmosed with the median caudal one. During its course, the lateral caudal vein drained the muscles, fascia and skin of the lateral and dorsal aspects of the respective side of the tail.

From the seventh caudal vertebra up to the distal end of the tail, the tail was mainly drained by the two lateral caudal veins (Fig., 14), which were the only recognizable veins in this area, where these veins connected each other at different levels by 3-4 transverse arcs (Fig., 14) on the dorsal aspect of the tail.

\section{Discussion}

The present study revealed that the arterial blood supply to the tail of the buffalo was obtained from the median caudal, superficial caudal, deep caudal, dorsolateral caudal and dorsal caudal arteries. However, El-Ayat, et al. (1983) in the same animal added the ventrolateral caudal artery instead of the dorsolateral caudal one. However, in camel they observed that the arteries of the tail were median caudal, ventral caudal, dorsal caudal, ventrolateral caudal and dorsolateral caudal arteries but in donkey, they demonstrated the median caudal, ventrolateral caudal and dorsolateral caudal arteries. Moreover, Evans and Christensen (1979) found seven longitudinal trunks in the proximal third of the tail as median caudal, paired superficial lateral caudal, paired ventrolateral caudal and paired dorsolateral caudal arteries in dog. The same finding in the majority of the domestic animals was obtained in this investigation as the main arterial supply of the tail came from the median caudal artery. However, Youssef and Alam El-Din (1991) considered the median sacral artery as the main arterial supply of the tail in sheep.

The present study detected that the union of the two lateral sacral arteries formed the median caudal artery. This result was the same as Bradley (1946), Raghavan and Kachroo (1964) and Sisson and Grossman (1968) in horse. However, El-Ayat et al., (1983) in buffalo and camel and Gadre (2000) in buffalo calves asserted that the median caudal artery was the caudal continuation of the median sacral one. However, in the species under investigation, this median sacral artery was absent and represented by the two lateral sacral arteries. This result cannot be matched with the later authors.

Similar to the findings of El-Ayat et al., (1983) in buffalo, the current investigation observed that the median caudal artery continued caudally through the vascular groove that was formed by the hemal processes of the caudal vertebrae in accompany with its homonymous vein and was embedded between the $M$. sacrocaudalis ventralis medialis of both sides and was covered by the caudal fascia, fat and skin up to its termination at the distal end of the tail.

The present work revealed that the median caudal artery along its course gave off superficial caudal and deep caudal branches. A result which was only detected by El-Ayat et al., (1983) in buffalo. The superficial caudal 
branches originated from the ventral aspect of the median caudal artery at regular intervals between adjacent caudal vertebrae to supply the skin, fascia and fat of the tail as observed by the current investigation and the later authors in buffalo. Moreover, the deep caudal branch of both sides originated by a common trunk from the dorsal aspect of the median caudal artery which immediately divided into right and left branches, a result which was in a line with the findings of the later authors.

The present study in buffalo revealed a different course for the deep caudal branches as they preceded caudodorsally deep to the ventral muscles of the tail and $\mathrm{Mm}$. intertransversarii caudae to gain the dorsal aspect of the transverse processes of the caudal vertebrae to anastmose with the epsilateral ones to constitute the dorsolateral caudal artery. However, El-Ayat et al. (1983) in the same animal observed that these branches ran ventral to the transverse processes to constitute the ventrolateral caudal artery. This artery was not detected in our investigation.

The dorsolateral caudal artery which was demonstrated by the current investigation in buffalo in addition to Ghoshal (1975) in ruminants and equine, Youssef and Alam El-Din (1991) in sheep and El-Ayat et al. (1983) in camel was not detected by El-Ayat et al. (1983) in buffalo. On the other hand, this artery behaved the same course and termination at the distal end of the tail as that observed by all aforementioned authors.

The present study revealed that the dorsolateral caudal artery issued small muscular branches to $\mathrm{Mm}$. intertransver-sarii caudae and several dorsal caudal branches that ramified within the dorsal muscles of the tail. Meanwhile, El-Ayat et al. (1983) in buffalo asserted that these dorsal caudal branches were detached from the ventrolateral caudal artery.

The present study reveled that the tail of the buffalo was drained by five caudal veins; one median caudal, two lateral caudal and two ventrolateral caudal veins. However, Binev, Gadzhiev, Gudev, and Gajev (1984) in the same animal and Brown and Carrow (1963) in bovines found only three veins; one median caudal and two lateral caudal veins.

The observations were obtained in this study differed from these of Yashwant and Dhingra (1976) in buffalo whereas the lateral caudal and ventrolateral caudal veins had no satellite arteries.

In the present study, the veins of the tail in the buffalo were anaestmosed to form arcs and loops, a fact that was observed in the median caudal artery of the same animal by Binev et al., (1984).

The same findings of most of the available literatures were observed in the current investigation as the median caudal vein represented the caudal continuation of the median sacral one in the region of the tail. However, in horse, Ghoshal et al., (1981) and Wilkens and Münster (1981) found that the median caudal vein was a stem from one of the caudal gluteal veins or it might be absent.

In this study, the median caudal vein coursed caudally on the left side of its homonymous artery up to the fifth caudal vertebra, where it gained the dorsal aspect of the artery. While, Schlerka, Baumgartner and Galle (1989) in cattle detected that the course of median caudal vein was inconstant. However, Youssef and Alam ElDin (1991) in sheep asserted that the median caudal vein up to the tip of the tail ran ventrally to its satellite artery. In pig, the paired median caudal veins situated dorsolaterally in the vascular groove and ran caudally on either sides of the median caudal artery as observed by Getty and Ghoshal (1967).

The ventrocaudal vein was well formed and its course was obviously demonstrated in our current investigation, Inspite of the observations of Binev et al., (1984) who asserted that the ventrolateral caudal vein is not well formed in the buffalo. At the seventh caudal vertebra, the ventrolateral caudal vein terminated by $2-3$ small branches, which anastmosed with the lateral caudal vein and terminal branches of the median caudal vein. During its course, the ventrolateral caudal vein drained the $\mathrm{Mm}$. intertransversarii caudae and ventral muscles of the tail. These results cannot be met with others.

The current investigation revealed that the two lateral caudal veins passed on the lateral aspect of the tail, between the $\mathrm{Mm}$. sacrocaudales dorsales laterales and $\mathrm{Mm}$. intertransversarii caudae and was covered by the caudal fascia and skin of the tail. Each lateral caudal vein anastmosed with the median caudal one behind the transverse processes of the first caudal vertebra. They drained the muscles, fascia and skin of the lateral and dorsal aspects of the tail. However, Ghoshal and Getty (1967) in ox observed that the lateral caudal veins were represented by a single vein, which was superficially situated on the right side of the tail up to the tenth caudal vertebra and terminated 
deeply under the muscles at the distal end of the tail.

\section{References}

Binev, K., Gadzhiev, S., Gudev, Kh. and Gajev, S. (1984): Blood vessel studies of the tail area of the domestic buffalo. Vet. Med. Nauki. Bulgaria, 21 (5): 61-65.

Bradley, O. C. (1946): The Topographical anatomy of the thorax and abdomen of the horse. Revised by T. Grahame, Second ed., W. Green and Son, Limited. Edinburgh.

Brown, R. and Carrow, R. (1963): Vascular anatomy of the bovine tail. J. Am. Vet. Med. Assoc., 143 (7): 12141215.

El-Ayat, M. A.; Hagras, S. M., Swielim, G. A. and Abuzaid, S. M. (1983): Anatomical studies on the arterial blood supply of the tail in certain domestic animals (Buffalo, Camel and Donkey). Vet. Med. J., Vol. 31, No (3): 245-254.

Evans, H. E. and Christensen, G. C. (1979): In Miller's anatomy of the dog. Second ed., W.B. Saunders Company Philadelphia, London, Sydney and Tokyo.

Gadre, K. M. (2000): Coccygeal artery of buffalo calves. Indian Vet. J., Vol. 77, No (1): 346.

Getty, R. and Ghoshal, N. G. (1967): Applied anatomy of the sacrococcygeal region of the pig as related to tailbleeding. Vet. Med. Small Animal Clinician; Vol. 62: 361367.

Ghoshal, N. G. and Getty, R. (1967): Applied anatomy of the sacrococcygeal region of the ox as related to tailBleeding. Vet. Med. Small Animal Clin., 62(1): 255-264.

Ghoshal, N. G. (1975): Heart and arteries in equine, ruminant and porcine. In: Sisson and Grossman's "The anatomy of the domestic animals". Revised by Getty, R. (1975). Fifth ed., W.B. Saunders Company Philadelphia, London, Toronto.
Hildebrand, M. (1968): Anatomical preparations. University of California Press. Barkeley and Los Anglos, California.

Nomina Anatomica Veterinaria (2005): Fifth edition, prepared by the International Committee on Veterinary Gross Anatomical Nomenclature (I.C.V.G.A.N.) and authorized by the General Assembly of the World Association of Veterinary Anatomists (W.A.V.A.) Knoxville, TN (U.S.A.) 2003.Published by the Editorial Committee Hanover, Columbia, Gent, Sapporo.

Raghavan, D. and Kachroo, P. (1964): Anatomy of the ox (With comparative notes on the horse, dog and fowl). Indian Council of Agricultural Research, New Delhi.

Schlerka, G., Baumgartner, W. and Galle, U. (1989): Risks of intravenous injection into the tail of cattle. Berl Munch Tieraztl Wochenschr, 102 (3): 77-84.

Sisson, S. and Grossman, J. D. (1968): The anatomy of the domestic animals, Fourth edition, W.B. Saunders Company, Philadelphia, London, Toronto.

Tawfiek, M. G. (2007): Some anatomical studies on the tail of the buffalo "Bos Bubalis L.". M.V.Sc., Thesis, Anatomy and Embryology, Fac. Vet. Med., Beni-Suef Univ., Beni-Suef, Egypt.

Wilkens, H. and Münster, W. (1981): The anatomy of the domestic animals. In: Nickel, R., Schummer, A. and Seiferle, E. (1981): Vol., (3): "The circulatory system, the skin and the cutaneous organs of the domestic animals". Verlag Paul Parey, Berlin, Hamburg.

Yashwant, S. and Dhingra, L. D. (1976): The blood vessels of tail in the buffalo. College of Vet. Sci., Haryana Agriculture University Hissar, India. Vol. 15, No (1):10-14. Youssef, M. A. and Alam El-Din M. A. (1991): Studies on the tail amputation in adult sheep. Assuit Vet. Med. J., 25 (50): 151-159.

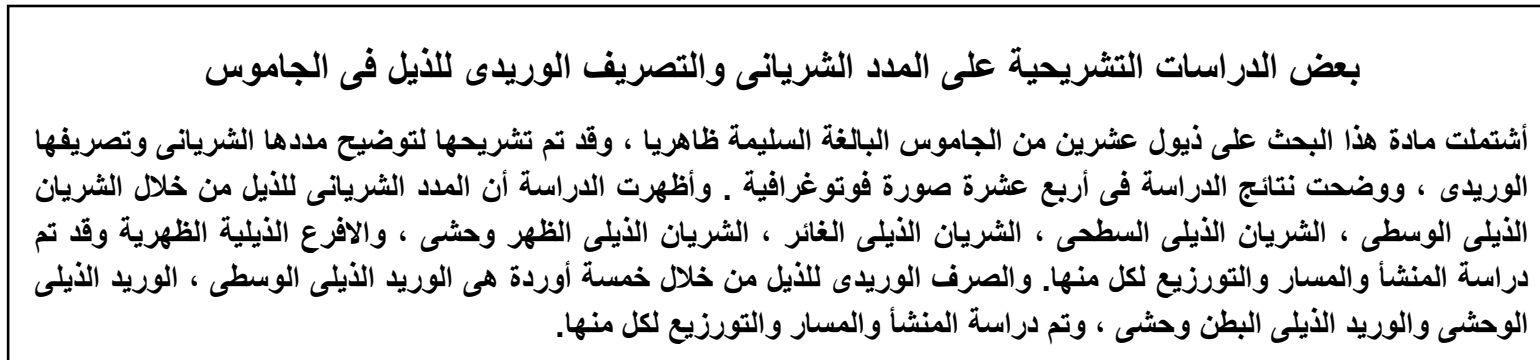

